\title{
AS COMPETÊNCIAS DE GESTORES DE PROJETOS QUE ATUAM COM MÉTODOS ÁGEIS E TRADICIONAIS: UM ESTUDO COMPARATIVO
}

\author{
THE COMPETENCIES OF PROJECT MANAGERS WORKING WITH AGILE AND \\ TRADITIONAL APPROACHES: A COMPARATIVE STUDY
}

\section{Resumo}

\author{
(D) Maria Paula Novakoski Perides \\ Doutoranda em Administração \\ Universidade de São Paulo - USP \\ São Paulo, SP - Brasil \\ paula.perides@usp.br \\ Erika Borgonovo Barrote \\ Mestranda em Administração \\ Universidade de São Paulo - USP \\ São Paulo, SP - Brasil. \\ erika.barrote@usp.br \\ Roberto Sbragia \\ Professor Titular Senior do Departamento de Administração \\ Universidade de São Paulo - USP \\ São Paulo, SP - Brasil. \\ rsbragia@usp.br
}

O mundo está se transformando rapidamente, forçando organizações a adaptarem seus processos para conseguir responder com agilidade a essas mudanças constantes. No cenário de gerenciamento de projetos, novas metodologias estão cada vez mais presentes, trazendo uma abordagem mais ágil e enxuta. Nesse contexto, o gerente de projetos com autoridade formal sobre a equipe está aos poucos dando lugar a um líder que atua mais como um facilitador, removendo obstáculos e promovendo a colaboração e o aprendizado contínuo. Assim, o objetivo deste artigo consiste em comparar as competências consideradas mais importantes para um gestor de projetos que atua predominantemente com metodologias Tradicionais e o líder de projetos que utiliza abordagens Ágeis. Para tal, foi realizada uma survey, utilizando um questionário online, submetido a profissionais que atuam em projetos. As 142 respostas válidas recebidas foram submetidas a análises estatísticas paramétricas por meio de análise de correspondência e de perfis, bem como não paramétricas, utilizando o método de coeficiente de correlação de postos de Kendall. As cinco competências consideradas mais importantes foram as mesmas para os dois grupos, mas ordenadas de maneira distinta. São elas: Integridade e Confiabilidade Pessoal, Comunicação Pessoal, Trabalho em Equipe, Estratégia e Relacionamentos e Engajamento. As análises estatísticas não permitiram concluir categoricamente que existem diferenças na percepção de importância das competências pelos profissionais que trabalham com metodologias Ágeis e Tradicionais, abrindo uma discussão bastante promissora sobre a maneira como essas novas abordagens estão sendo incorporadas pelas organizações e percebidas por seus profissionais.

Palavras-chave: Competências. Metodologias de Gerenciamento de Projetos. Metodologias Ágeis. Liderança de Projetos.

\section{Abstract}

The world is rapidly changing, forcing organizations to adapt their processes in order to respond quickly to these constant changes. In the project management scenario, new methodologies are 
increasingly present, bringing a more agile and lean approach. In this context, the project manager with formal authority over the team is gradually giving way to a leader who acts more as a facilitator, removing obstacles and promoting collaboration and continuous learning. Thus, the objective of this article is to compare the competencies considered most important for a project manager who works predominantly with Traditional methodologies and the project leader who uses Agile approaches. For this, a survey was carried out, using an online questionnaire, submitted to professionals working on projects. The 142 valid responses received were subjected to parametric through correspondence and profile analysis, as well as non-parametric statistical analysis, using Kendall's rank correlation coefficient method. The five competencies considered most important were the same for the two groups, but they were ordered in different ways. They are: Personal Integrity and Reliability, Personal Communication, Teamwork, Strategy and Relationships and Engagement Statistical analyzes did not allow categorically concluding that there are differences in the perception of the importance of skills by professionals working with Agile and Traditional methodologies, opening a very promising discussion about the way in which these new approaches are being incorporated by organizations and perceived by its professional.

Keywords: Competencies. Project Management Methodologies. Agile Methodologies. Project Leadership.

\section{Cite como - American Psychological Association (APA)}

Perides, M. P. N., Barrote, E. B., \& Sbragia R. (2021, Ed. Esp. jan./abr.). As competências de gestores de projetos que atuam com métodos ágeis e tradicionais: um estudo comparativo. Revista de Gestao e Projetos (GeP), 12(1), 11-38. https://doi.org/10.5585/gep.v12i1.17534.

\section{Introdução}

O mundo globalizado e tecnologicamente conectado tem pressionado as empresas a reinventar seus modelos de negócio à medida que novos concorrentes criam produtos ou serviços inovadores com a ajuda das tecnologias digitais, entregando resultados de forma cada vez mais rápida e eficaz (Gerster, Dremel, Brenner, \& Kelker, 2020).

Para atender a essa demanda, novas metodologias e processos de trabalho têm sido implementados com o objetivo de agilizar o desenvolvimento de novos produtos e serviços. A gestão de projetos, como uma competência essencial das organizações para lidar com empreendimentos novos e inovadores, também precisou se adaptar. Nesse contexto, surgem as abordagens Ágeis, com a proposta inicial de tornar o processo de criação e desenvolvimento de inovações mais rápido e eficaz, focando principalmente na entrega de valor para o cliente (Denning, 2019; Erickson, Lyytinen, \& Siau, 2005).

Os gerentes de projetos, por sua vez, passaram a ser mais exigidos, sendo obrigados a se aperfeiçoarem não apenas em suas habilidades e atitudes para solucionar problemas, mas também em suas competências de relacionamento e metodologias de trabalho (Chipulu, Neoh, Ojiako, \& Williams, 2013; Noro \& Bronzatti, 2013). No ambiente de 
Perides, M. P. N., Barrote, E. B., \& Sbragia R. (2021, Ed. Esp. jan./abr.). As competências de gestores de projetos que atuam com métodos ágeis e tradicionais: um estudo comparativo

inovação, o gerente de projetos Tradicional, que atuava de forma hierárquica junto a sua equipe, distribuindo recursos, priorizando ações, avaliando e decidindo, tem seu papel modificado. Surge o líder de projetos Ágil, que atua como um membro do time, buscando remover obstáculos e apoiar a equipe, que conta agora com profissionais mais maduros e que gerenciam a si mesmos. Nesse modelo, não há mais a relação hierárquica de poder e decisão que existia antes, incorporada na função dos gerentes de projetos que utilizavam o método Tradicional (Boehm \& Turner, 2005; Nerur, Mahapatra, \& Mangalaraj, 2005; PMI, 2017a).

Vale ressaltar que as práticas Ágeis se adequam melhor a projetos onde há necessidade de inovações e mudanças constantes, e onde o cliente seja próximo o suficiente para colaborar e oferecer feedbacks constantes (Cockburn \& Highsmith, 2001; Denning, 2016b; Rigby, Sutherland, \& Takeuchi, 2016). As metodologias Tradicionais continuam sendo largamente utilizadas e apresentam bons resultados quando o escopo do projeto é estável, ou quando sofre poucas mudanças ao longo do seu ciclo de vida (PMI, 2016). Algumas empresas passam então a lidar simultaneamente com dois ambientes de projetos, adotando para cada empreendimento o método de gestão mais adequado, ou combinando os métodos em abordagens híbridas. Nessa situação, dois fatores que se tornam muito importantes são o perfil das pessoas, incluindo seus estilos de liderança e a estrutura organizacional da qual o projeto faz parte (Garcia \& Russo, 2019).

A literatura acadêmica é farta em estudos sobre as competências necessárias aos gerentes de projetos, mas não consideram a metodologia de gerenciamento utilizada. Cheng, Dainty e Moore (2005) pesquisaram as competências comportamentais mais importantes para gerentes de projeto na indústria da construção e compararam seus achados com estudos de competências para gerentes de outras áreas de atuação. Os autores concluíram que, apesar de utilizarem nomenclaturas diferentes, existe um conjunto universal de competências comportamentais genéricas utilizáveis como base para o desenvolvimento da gestão em muitos ambientes de trabalho, como orientação para resultados, iniciativa, foco nas necessidades do cliente, liderança da equipe, entre outras (Cheng et al., 2005). Stevenson e Starkweather (2010) também pesquisaram as competências mais importantentes para o gerente de projetos, mas focados na indústria de Tecnologia da Informação. Müller e Turner (2010) verificaram se as competências importantes para o gerente de projetos variam de acordo com o tipo de aplicação, complexidade, importância e tipo de contrato. Os resultados indicaram variações nas quatro categorias.

Loufrani-Fedida e Missonier (2015) propõem um modelo de competências multinivel, onde as competências críticas para o projeto não são centralizadas na figura do gerente, mas na competência coletiva da 
Perides, M. P. N., Barrote, E. B., \& Sbragia R. (2021, Ed. Esp. jan./abr.). As competências de gestores de projetos que atuam com métodos ágeis e tradicionais: um estudo comparativo

equipe. Matook e Maruping (2014), por sua vez, definiram um modelo de competências focado em ambientes que adotam as abordagens Ágeis, mas com foco específico nos representantes do cliente que atuam como membros da equipe do projeto. Garcia e Russo (2019) analisaram a relação existente entre a liderança e o desempenho da equipe, verificando que o método de gestão de projetos utilizado não influencia nessa relação.

Por ser uma figura recente no cenário organizacional, o líder que trabalha com metodologias Ágeis ainda não possui grande suporte literário científico, não tendo sido encontrados estudos que explorem se o tipo de metodologia utilizado pode impactar nas competências consideradas mais importantes para seu bom desempenho. Assim, este estudo tem como objetivo comparar as competências consideradas mais importantes para um gestor de projetos que atua predominantemente com metodologias Tradicionais e o líder de projetos que utiliza abordagens Ágeis, de acordo com os profissionais que atuam com essas abordagens.

Do ponto de vista teórico, o estudo se justifica pelo fato de tratar de competências em um ambiente de projetos ainda pouco explorado pela literatura (Cram \& Marabelli, 2018; Kregel, Ogonek, \& Matthies, 2019). Em termos práticos, a relevância consiste em oferecer subsídios para compreender quais competências os líderes de projetos devem buscar e/ou aprimorar para atuar em um ambiente organizacional cada vez mais complexo.

\section{Fundamentação teórica}

Para contextualizar o objeto deste estudo e seus resultados, este tópico descreve inicialmente um breve histórico sobre as metodologias de gerenciamento de projetos, tanto Tradicionais quanto Ágeis. Em seguida, é apresentado o conceito de competências e, por fim, são tratadas mais especificamente as competências necessárias para a liderança de projetos.

\subsection{Metodologias de gerenciamento de projetos}

As metodologias de gerenciamento de projetos remontam aos anos 1960 com os primeiros projetos de desenvolvimento de software realizados pela NASA (Larman \& Basili, 2003). A primeira associação mundial de gerenciamento de projetos foi criada em 1965 e hoje é conhecida como International Project Management Association (IPMA). Quatro anos depois, foi fundado o Project Management Institute (PMI), que é conhecido como o editor do Guia do Conhecimento em Gerenciamento de Projetos (Guia PMBOK®). O livro é uma compilação de processos e áreas de conhecimento geralmente aceitos como melhores práticas de gerenciamento de projetos e se tornou um padrão para a indústria (Seymour \& Hussein, 2014). Mas é em 1970, com a publicação do famoso artigo "Gerenciando o Desenvolvimento de grandes 
Perides, M. P. N., Barrote, E. B., \& Sbragia R. (2021, Ed. Esp. jan./abr.). As competências de gestores de projetos que atuam com métodos ágeis e tradicionais: um estudo comparativo

Sistemas de Software" (Managing the Development of Large Software Systems) de Winston Royce, que surge o conceito de ciclo de vida do projeto, dividido em fases sequenciais e que mais tarde ficou conhecido como metodologia "Cascata" ou "Tradicional" (Rajagopalan, 2014).

A filosofia do modelo em cascata foi herdada dos processos de indústrias de fabricação de hardware e de construção civil, que estavam em prática durante a década de 1970, por isso tem abordagem bastante estruturada. Essas metodologias trabalham com o ciclo de vida preditivo, onde o escopo, o prazo e o custo do projeto são definidos em sua fase inicial, durante o planejamento do projeto. Uma vez aprovado o planejamento, qualquer mudança no escopo deve ser cuidadosamente gerenciada, pois impactará os prazos e/ou custos acordados (Nerur et al., 2005; PMI, 2016). Assim, os adeptos dessas metodologias defendem o planejamento extensivo, os processos codificados e a reutilização rigorosa, de forma a tornar a execução uma fase eficiente e previsível (Dybå \& Dingsøyr, 2008).

Nas organizações que adotam as metodologias Tradicionais, os projetos são coordenados pelo gerente de projetos, que "é a pessoa designada pela organização executora para liderar a equipe responsável por alcançar os objetivos do projeto" (PMI, 2016, p. 52). Neste cenário, o gerente atua como um maestro de sua equipe. Ele deve ter uma visão holística dos objetivos do projeto e é responsável por coordenar os esforços de planejamento, execução e conclusão de todas as atividades, garantindo que a entrega do projeto vai permitir o alcance dos objetivos acordados com o cliente (PMI, 2016).

As metodologias Tradicionais vêm sendo largamente utilizadas em projetos nos vários segmentos de negócios, apresentando bons resultados quando o escopo do projeto é estável ou quando sofre poucas mudanças ao longo do seu ciclo de vida. No entanto, essa não é a realidade da indústria de software, que no final dos anos 1990 apresentava uma sucessão de casos de fracasso. Em 1994, o The Standish Group publicou seu famoso relatório The Chaos Report (1994), com o resultado de uma pesquisa que apontava para uma taxa de sucesso de apenas 16,2\% nos projetos de desenvolvimento de software. Em sua conclusão, o relatório apontava que os principais motivos para o fracasso de tantos projetos estavam associados ao uso das metodologias tradicionais ou "cascata" (The Standish Group International, 1994).

Em 2001, 17 profissionais especialistas em desenvolvimento de software reuniram-se em Snowbird (Utah, EUA) para discutir os principais motivos que levavam os projetos desse segmento a tantos atrasos e fracassos. Desse encontro resultou o Manifesto Ágil, composto de 4 valores e 12 princípios (Beck et al., 2001), que valorizam os indivíduos e interações acima de processos e ferramentas, o funcionamento do software acima da documentação completa, a 
Perides, M. P. N., Barrote, E. B., \& Sbragia R. (2021, Ed. Esp. jan./abr.). As competências de gestores de projetos que atuam com métodos ágeis e tradicionais: um estudo comparativo

colaboração com o cliente acima da negociação do contrato e resposta rápida às mudanças sempre que necessário.

Em projetos que adotam metodologias Ágeis é esperado que existam mudanças frequentes de requisitos durante seu desenvolvimento. Assim, os requisitos são abordados de maneira mais interativa e as entregas são feitas em ciclos mais curtos, de forma incremental, ao longo de todo o projeto.
$\mathrm{Na}$ medida em que as entregas vão sendo realizadas, a equipe é retroalimentada com feedbacks dos clientes, evitando retrabalho (Ambler \& Lines, 2020; Nerur et al., 2005; PMI, 2017a)

Nerur et al. (2005) fizeram um comparativo entre os dois tipos de abordagens - Tradicional e Ágil - e sintetizaram as principais diferenças, como mostra o Quadro 1.

Quadro 1 - Gerenciamento tradicional e ágil de projetos

\begin{tabular}{|c|c|c|}
\hline & TRADICIONAL & ÁGIL \\
\hline Premissas Básicas & $\begin{array}{l}\text { Os produtos são totalmente } \\
\text { especificáveis, previsíveis e podem } \\
\text { ser construídos por meio de } \\
\text { planejamento meticuloso e e } \\
\text { abrangente. }\end{array}$ & $\begin{array}{l}\text { O produto adaptável, de alta qualidade, pode } \\
\text { ser desenvolvido por pequenas equipes } \\
\text { usando os princípios de melhoria contínua } \\
\text { de design e testes baseados em feedback e } \\
\text { mudanças rápidas. }\end{array}$ \\
\hline Controle & Centrado no processo & Centrado nas pessoas \\
\hline Estilo de Gestão & Comando e controle & Liderança e colaboração \\
\hline $\begin{array}{l}\text { Gestão do } \\
\text { Conhecimento }\end{array}$ & Explícito & Tácito \\
\hline Atribuição de Função & $\begin{array}{l}\text { Individual }- \text { favorece } \quad \text { a } \\
\text { especialização }\end{array}$ & $\begin{array}{l}\text { Equipes de auto-organizadas, incentivando a } \\
\text { troca de funções }\end{array}$ \\
\hline Comunicação & Formal & Informal \\
\hline Papel do Cliente & Importante & Crítico \\
\hline Ciclo do projeto & Guiado por tarefas ou atividades & Guiado por recursos do produto \\
\hline $\begin{array}{l}\text { Modelo de } \\
\text { Desenvolvimento }\end{array}$ & $\begin{array}{l}\text { Modelo de ciclo de vida (cascata, } \\
\text { espiral, ou alguma variação) }\end{array}$ & Modelo de entregas evolutivas \\
\hline $\begin{array}{l}\text { Estrutura } \\
\text { Organizacional Ideal }\end{array}$ & $\begin{array}{l}\text { Hierárquica (burocrático com alta } \\
\text { formalização) }\end{array}$ & $\begin{array}{l}\text { Orgânica (flexível e participativa, } \\
\text { encorajando a colaboração) }\end{array}$ \\
\hline Tecnologia & Sem restrição & Favorece a tecnologia orientada a objetos \\
\hline
\end{tabular}

Fonte: Nerur et al. (2005, p. 75, tradução nossa). 
Idealmente, as equipes Ágeis devem ser pequenas (de 3 a 9 pessoas), dedicadas em tempo integral ao projeto, multidisciplinares com todos os perfis necessários para a execução do trabalho e autogerenciáveis (PMI, 2017a; Rigby et al., 2016). Como não há hierarquia entre os membros da equipe, todos são responsáveis pelas entregas. O trabalho é realizado em ciclos curtos com tarefas relativamente pequenas que agregam valor aos clientes e com feedback contínuo dos usuários finais (Denning, 2016b; PMI, 2017a; Rigby et al., 2016).

Nesse ambiente surge a figura do "líder servidor", cujo papel é muito mais de um "facilitador" que de um "coordenador". Entre suas principais responsabilidades podese destacar a construção de relacionamentos, o incentivo à colaboração e a remoção dos obstáculos organizacionais para a realização do projeto (Nerur et al., 2005; PMI, 2017a). Deve também atuar como uma barreira entre a organização e a equipe, evitando perturbações desnecessárias durante o desenvolvimento das atividades (Boehm \& Turner, 2005). É a equipe que decide o trabalho que deve ser realizado a cada ciclo, estima o tempo que levará para sua execução e como ele será executado. Ao final de cada ciclo a equipe avalia seu desempenho e pensa em ações de melhoria para os ciclos futuros (Denning, 2016b; Rigby et al., 2016).

Tanto as abordagens Ágeis como as Tradicionais têm pontos fortes e fracos, e assim uma única abordagem não é adequada para todos os tipos de projetos (Barlow et al., 2012) Muitas vezes, as equipes de projeto selecionam um subconjunto das práticas Ágeis e Tradicionais, criando sua própria metodologia. São as chamadas abordagens híbridas (Gill, Henderson-Sellers, \& Niazi, 2018).

\subsection{Competências}

O conceito de competência como maneira de avaliar o potencial de candidatos a vagas de emprego ou instituições de ensino foi proposto pela primeira vez em 1973, por David McClelland, como alternativa aos testes de inteligência, muito comuns naquela época. McClelland pesquisou os principais fatores que fizeram com que profissionais de sucesso tivessem êxito em suas funções $\mathrm{e}$ se destacassem dos demais. A esses fatores o autor chamou de competências diferenciadoras. $\mathrm{O}$ autor verificou, então, que tais competências poderiam ser ensinadas a outros profissionais (McClelland, 1973).

Em seguida, o autor propôs a definição das competências diferenciadoras necessárias para cada cargo de uma organização e sua comparação com as competências dos profissionais que ocupavam esses cargos. Dessa forma, tornou-se possível analisar a lacuna ( $g a p$ ) entre o perfil ideal para a vaga e o perfil real do funcionário (McClelland, 1973) e avaliar os pontos que deveriam ser desenvolvidos. No Brasil, as 
Perides, M. P. N., Barrote, E. B., \& Sbragia R. (2021, Ed. Esp. jan./abr.). As competências de gestores de projetos que atuam com métodos ágeis e tradicionais: um estudo comparativo

competências diferenciadoras definidas por McClelland ficaram conhecidas como "CHA", um mnemônico para Conhecimento, Habilidades e Atitudes, e foi rapidamente adotado por várias organizações (Dutra, 2017).

Boyatzis (1982) amplia a definição de McClelland ao trazer para o conceito de competências uma preocupação com as entregas do profissional para a organização.

Segundo o autor, as competências representam a capacidade de influenciar em uma situação de trabalho, bem como tomar ações apropriadas. Tais ações serão consideradas apropriadas quando o desempenho do trabalho for efetivo, isto é, quando as competências, as demandas do trabalho e as condições do ambiente organizacional estiverem consistentes e adequadas. Assim, apesar de as competências serem necessárias, elas não são suficientes para o desempenho efetivo no trabalho (Boyatzis, 1982).

Le Boterf (2003) aprofunda ainda mais a associação de competência à ideia de geração de valor. Segundo o autor "a competência se personificará em práticas profissionais que terão um impacto sobre os desempenhos realizados" (Le Boterf, 2003, p. 47). Le Boterf comenta ainda que existem diferentes ações para solucionar um problema com competência e que saber agir, por vezes, pode significar não agir. Sendo assim, eventualmente a utilização do termo "reação" seria mais apropriada do que "ação", já que uma boa reação pode ser a não-intervenção (Le Boterf, 2003). Finalmente, ainda de acordo com o autor, a competência não é uma constante, e pode variar em função da evolução da situação em que intervém (Le Boterf, 2003).

Cabe ainda destacar a definição de competências estabelecida por Fleury e Fleury (2000, p. 21) como "o saber agir responsável e reconhecido, que implica mobilizar, integrar, transferir conhecimentos, recursos, habilidades, que agreguem valor econômico à organização e valor social ao indivíduo".

\subsection{Competências dos líderes de projetos}

À medida que as metodologias de gerenciamento de projetos começaram a ser largamente utilizadas em diversos setores industriais, surgiram órgãos buscando desenvolver padrões e programas de certificação para essa prática. Esses órgãos tiveram um impacto importante na direção do gerenciamento de projetos, se tornando uma bússola de sua condução (Stevenson \& Starkweather, 2010).

O PMI classificou as competências do gerente de projetos em três grupos: a) conhecimento - relacionadas ao grau de conhecimento das práticas de gerenciamento de projetos; b) performance - relacionada à maneira como o gerente aplica esse conhecimento e os resultados obtidos; c) pessoais - relacionadas ao comportamento e às habilidades do gerente no que diz respeito à comunicação, liderança, gestão, habilidades cognitivas, eficácia e profissionalismo (PMI, 2017b). 
Perides, M. P. N., Barrote, E. B., \& Sbragia R. (2021, Ed. Esp. jan./abr.). As competências de gestores de projetos que atuam com métodos ágeis e tradicionais: um estudo comparativo

O IPMA desenvolveu um framework de competências inicialmente focado nos gerentes que atuam com projetos Tradicionais (IPMA, 2015) e, posteriormente, adaptou-o aos ambientes Ágeis (IPMA, 2018). Os dois modelos contam com as mesmas 28 competências, porém as habilidades e

Quadro 2 - Competências do gerente de projetos

\begin{tabular}{|c|c|c|}
\hline \multirow{5}{*}{ Perspectiva } & Estratégia & $\begin{array}{l}\text { Alinhar equipe com a missão e propósito do projeto, } \\
\text { bem como determinar e analisar seus principais } \\
\text { indicadores de desempenho. }\end{array}$ \\
\hline & Governança, estruturas e processos & $\begin{array}{l}\text { Conhecer e aplicar as melhores práticas para } \\
\text { execução do trabalho e alinhá-las com os processos } \\
\text { das demais áreas da organização. }\end{array}$ \\
\hline & $\begin{array}{l}\text { Conformidade, normas e } \\
\text { regulamentos }\end{array}$ & $\begin{array}{l}\text { Garantir que o trabalho está em conformidade com } \\
\text { toda a legislação, regulamentação, códigos e } \\
\text { princípios relevantes. }\end{array}$ \\
\hline & Poder e interesse & $\begin{array}{l}\text { Avaliar as ambições pessoais e interesses dos } \\
\text { indivíduos e seu impacto potencial no resultado do } \\
\text { projeto. }\end{array}$ \\
\hline & Cultura e valores & $\begin{array}{l}\text { Avaliar a cultura formal e informal, bem como os } \\
\text { valores da organização e suas implicações para o } \\
\text { trabalho do projeto. }\end{array}$ \\
\hline \multirow{7}{*}{ Pessoas } & Autorreflexão e autogestão & $\begin{array}{l}\text { Construir a autoconfiança com base em forças e } \\
\text { fraquezas pessoais, assumindo a responsabilidade } \\
\text { pelo aprendizado e desenvolvimento pessoal. }\end{array}$ \\
\hline & Integridade e confiabilidade pessoal & $\begin{array}{l}\text { Reconhecer e aplicar valores éticos a todas as } \\
\text { decisões e ações, assumindo a responsabilidade por } \\
\text { suas decisões e ações. }\end{array}$ \\
\hline & Comunicação pessoal & $\begin{array}{l}\text { Escolher estilos e canais de comunicação adequados } \\
\text { para atender às necessidades de cada público. } \\
\text { Facilitar e promover uma comunicação aberta. }\end{array}$ \\
\hline & Relacionamentos e engajamento & $\begin{array}{l}\text { Mostrar confiança e respeito, incentivando os outros } \\
\text { a compartilhar suas opiniões ou preocupações, } \\
\text { criando e desenvolvendo relacionamentos pessoais e } \\
\text { profissionais baseados em confiança. }\end{array}$ \\
\hline & Liderança & $\begin{array}{l}\text { Exercer poder e influência apropriados sobre os } \\
\text { outros para alcançar os objetivos do projeto, além de } \\
\text { proporcionar orientação, coaching e mentoring para } \\
\text { melhorar o trabalho dos indivíduos e da equipe. }\end{array}$ \\
\hline & Trabalho em equipe & $\begin{array}{l}\text { Promover a cooperação e o trabalho em rede entre os } \\
\text { membros da equipe, facilitando o aprendizado e } \\
\text { inspirando a melhoria contínua. }\end{array}$ \\
\hline & Conflito e crise & $\begin{array}{l}\text { Mediar e resolver conflitos e crises envolvendo a } \\
\text { equipe e as partes interessadas. }\end{array}$ \\
\hline
\end{tabular}

comportamentos associados a cada uma podem mudar, dependendo do tipo de metodologia utilizada. Essas competências foram classificadas em três categorias: perspectiva, pessoas e prática, como pode ser visto no Quadro 2. 
Perides, M. P. N., Barrote, E. B., \& Sbragia R. (2021, Ed. Esp. jan./abr.). As competências de gestores de projetos que atuam com métodos ágeis e tradicionais: um estudo comparativo

\begin{tabular}{|c|c|c|}
\hline & Desenvoltura & $\begin{array}{l}\text { Estimular e apoiar um ambiente aberto e criativo, } \\
\text { promovendo uma visão holística que propicie o } \\
\text { surgimento de novas alternativas e soluções. }\end{array}$ \\
\hline & Negociação & $\begin{array}{l}\text { Definir uma estratégia de negociação que atenda aos } \\
\text { objetivos do projeto que esteja alinhada com os } \\
\text { interesses de todas as partes envolvidas. }\end{array}$ \\
\hline & Orientação para resultado & $\begin{array}{l}\text { Avaliar decisões e ações em relação ao seu impacto } \\
\text { no valor do cliente e nas metas da organização, } \\
\text { buscando sempre otimizar o resultado do projeto. }\end{array}$ \\
\hline \multirow{13}{*}{ Prática } & Desenho do projeto & $\begin{array}{l}\text { Facilitar um entendimento dos critérios de sucesso do } \\
\text { projeto e adotar uma abordagem de gerenciamento } \\
\text { adequada a estes objetivos. }\end{array}$ \\
\hline & Requisitos, objetivos e benefícios & $\begin{array}{l}\text { Definir a visão e priorizar os requisitos para } \\
\text { maximizar o valor entregue ao cliente. }\end{array}$ \\
\hline & Escopo & $\begin{array}{l}\text { Estruturar a solução e definir as entregas com foco no } \\
\text { valor para o cliente. }\end{array}$ \\
\hline & Tempo & $\begin{array}{l}\text { Sequenciar as atividades e entregas, estimar o esforço } \\
\text { e monitorar o andamento com relação ao planejado. }\end{array}$ \\
\hline & Organização e informação & $\begin{array}{l}\text { Definir a estrutura, as funções e as responsabilidades } \\
\text { dentro do projeto, bem como determinar um fluxo de } \\
\text { informações que atenda às necessidades das partes } \\
\text { interessadas. }\end{array}$ \\
\hline & Qualidade & $\begin{array}{l}\text { Desenvolver, monitorar a implementação e revisar } \\
\text { regras de qualidade para o projeto que garantam } \\
\text { qualidade em todas as entregas. }\end{array}$ \\
\hline & Custos & $\begin{array}{l}\text { Estimar os custos do projeto, definindo um } \\
\text { orçamento, e monitorar as finanças para identificar e } \\
\text { corrigir eventuais desvios }\end{array}$ \\
\hline & Recursos & $\begin{array}{l}\text { Desenvolver planos de recursos estratégicos para o } \\
\text { projeto, definindo a quantidade e a qualidade } \\
\text { necessários, bem como monitorar sua alocação } \\
\text { corrigindo eventuais desvios. }\end{array}$ \\
\hline & Aquisições e parcerias & $\begin{array}{l}\text { Avaliar a necessidade de aquisições, contribuir para a } \\
\text { avaliação e seleção de fornecedores e parceiros e } \\
\text { supervisionar a execução dos contratos. }\end{array}$ \\
\hline & Planejar e controlar & $\begin{array}{l}\text { Desenvolver e aprovar o plano de gerenciamento do } \\
\text { projeto, gerenciar a transição para cada nova fase ou } \\
\text { release e monitorar o desempenho de forma } \\
\text { transparente. }\end{array}$ \\
\hline & Risco e oportunidades & $\begin{array}{l}\text { Identificar riscos e oportunidades, avaliando seu } \\
\text { impacto e probabilidade, definindo estratégias para } \\
\text { lidar com eles e monitorando sua ocorrência. }\end{array}$ \\
\hline & Partes interessadas & $\begin{array}{l}\text { Desenvolver e manter uma estratégia de engajamento } \\
\text { das partes interessadas e um plano de comunicação. }\end{array}$ \\
\hline & Mudança e transformação & $\begin{array}{l}\text { Avaliar a adaptabilidade da organização a mudanças } \\
\text { e desenvolver e implementar uma estratégia de } \\
\text { gerenciamento de mudanças e/ou transformação. }\end{array}$ \\
\hline
\end{tabular}

Fonte: Adaptado de IPMA $(2015,2018)$. 
Todos esses frameworks consideram que as competências necessárias aos gerentes de projeto são as mesmas, independente da abordagem utilizada. No entanto, tendo em vista as principais diferenças entre $o$ gerenciamento Tradicional e Ágil de projetos, explicitados no Quadro 1, é possível que a percepção de importância dessas competências varie de acordo com o tipo de metodologia empregada. Assim, elaborou-se a primeira hipótese deste estudo:

H1: O tipo de metodologia de gerenciamento de projetos (Ágil ou Tradicional) utilizado influencia a percepção de importância das competências dos líderes de projeto.

Como metodologias Ágeis estão associadas a ambientes predominantemente jovens e com muitas mudanças, levantou-se também a hipótese de que a senioridade dos respondentes poderia, de alguma maneira, influenciar a percepção sobre a importância dessas competências, dando origem à segunda hipótese:

H2: Profissionais mais seniores têm visão diferente das competências mais importantes para líderes de projeto do que profissionais mais juniores.

Da mesma maneira, o porte da empresa pode ser um influenciador dessa percepção, uma vez que profissionais de pequenas empresas, do tipo startup, podem ter uma percepção diferente quando comparados aos profissionais que atuam em grandes organizações. Essa consideração fundamentou a terceira hipótese desse estudo:

H3: Profissionais que trabalham em empresas com muitos funcionários (mais de 1000) têm visão diferente das competências mais importantes para líderes de projeto do que profissionais que atuam em empresas menores.

\section{Procedimentos metodológicos}

A presente pesquisa tem por objetivo comparar as competências consideradas mais importantes para um gestor de projetos que atua predominantemente com metodologias Tradicionais e o líder de projetos que utiliza abordagens Ágeis. No que diz respeito aos objetivos, trata-se de uma pesquisa descritiva. Nesse tipo de pesquisa busca-se analisar a descrição das características de determinada população ou fenômeno ou o estabelecimento de relações entre as variáveis (Gil, 2010). A estratégia de pesquisa adotada é a survey, onde a obtenção dos dados e informações que se deseja levantar é feita através de um instrumento de pesquisa pré-definido, normalmente um questionário (Freitas, Oliveira, Saccol, \& Moscarola, 2000).

Com base na fundamentação teórica e nas hipóteses desenvolvidas, foi proposto pelos autores, o modelo de pesquisa da Figura 1. 
Figura 1 - Modelo conceitual do estudo

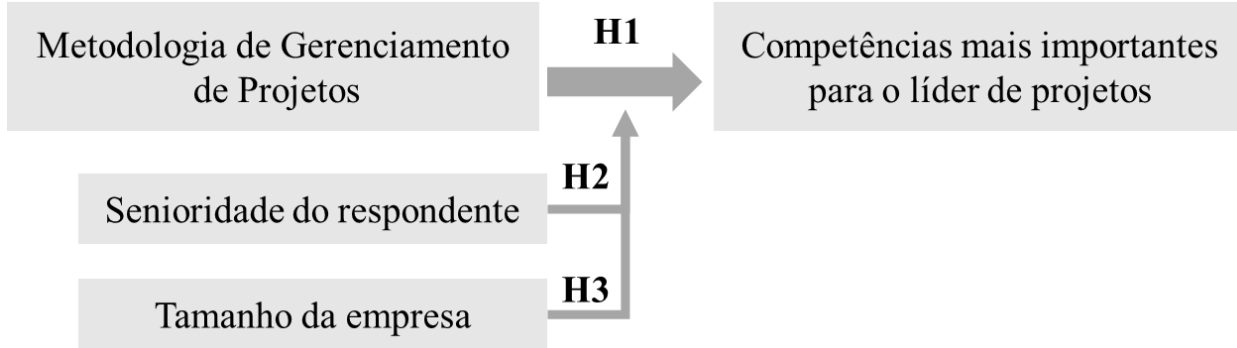

Fonte: Elaborada pelos autores (2020).

Para efeito da escolha dos fatores de competências que deveriam ser avaliados pela comunidade de profissionais que atuam em projetos, avaliou-se as competências apresentadas nos modelos do IPMA e do PMI, detalhados na seção anterior. Como resultado, optou-se por trabalhar com o framework do IPMA, por ser considerado mais abrangente e já estar caracterizado tanto para ambientes Tradicionais como para ambientes Ágeis. Além do mais, é um dos modelos mais aceitos pela comunidade científica internacional enquanto proveniente de uma comunidade prática.

Em termos de procedimentos de campo, uma pergunta inicial foi feita para a seleção dos respondentes, de forma a garantir que todos trabalhavam com projetos. Em seguida, foram feitas algumas questões classificatórias, identificando o tipo de metodologia predominantemente utilizada no ambiente do respondente (Tradicional ou Ágil), sua função na equipe, seu tempo de experiência trabalhando com projetos, seu grau de conhecimento sobre metodologias de gerenciamento de projetos e a quantidade de profissionais da empresa onde trabalha. Em seguida, cada uma das competências foi avaliada individualmente utilizando uma escala Likert de 5 pontos, onde 1 significava "Sem Importância" e 5 significava "Extremamente Importante". No final, os respondentes indicaram, em uma única pergunta, quais, dentre as 28 competências apresentadas em conjunto, eram as 3 que consideravam mais importantes. Ou seja, as competências primeiramente foram apresentadas uma a uma, para que os participantes as avaliassem sem que conseguissem visualizar as perguntas posteriores, mas ao final, dentre todas as 28 competências apresentadas, poderiam optar pelas 3 que acreditavam ser as mais importantes.

Um pré-teste foi realizado com dois profissionais experientes, que sugeriram pequenos ajustes em algumas das descrições utilizadas. O questionário, em sua forma final, 
Perides, M. P. N., Barrote, E. B., \& Sbragia R. (2021, Ed. Esp. jan./abr.). As competências de gestores de projetos que atuam com métodos ágeis e tradicionais: um estudo comparativo

foi elaborado na ferramenta Google Forms e o link correspondente foi enviado aos participantes da amostra então constituída. Tal amostra foi selecionada por conveniência nas redes sociais dos autores e por listas de e-mails de entidades relacionadas ao segmento profissional. As respostas obtidas totalizaram 175 respondentes, sendo que 142 trabalhavam com projetos, compondo um percentual de

Tabela 1 - Características da amostra pesquisada

\begin{tabular}{|c|c|c|c|c|}
\hline Metodologia & & & Total & $\%$ \\
\hline Ágil ou Híbrido com predo & ninânci & e Ágil & 59 & $42 \%$ \\
\hline $\begin{array}{l}\text { Tradicional (Cascata) ou H } \\
\text { predominância de Tradicior }\end{array}$ & $\begin{array}{l}\text { brido co } \\
\text { al }\end{array}$ & & 83 & $58 \%$ \\
\hline Total & & & 142 & \\
\hline Conhecimento & Trad. & Ágil & Total & $\%$ \\
\hline Especialista & 23 & 16 & 39 & $27 \%$ \\
\hline Muito Conhecimento & 32 & 25 & 57 & $40 \%$ \\
\hline Médio Conhecimento & 25 & 15 & 40 & $28 \%$ \\
\hline Pouco Conhecimento & 1 & 3 & 4 & $3 \%$ \\
\hline Nenhum Conhecimento & 2 & 0 & 2 & $1 \%$ \\
\hline Total & 83 & 59 & 142 & \\
\hline Funcionários na empres & Trad. & Ágil & Total & $\%$ \\
\hline De 1 a 10 & 3 & 6 & 9 & $6 \%$ \\
\hline De 11 a 50 & 8 & 3 & 11 & $8 \%$ \\
\hline De 51 a 200 & 9 & 12 & 21 & $15 \%$ \\
\hline De 201 a 500 & 4 & 5 & 9 & $6 \%$ \\
\hline De 501 a 1000 & 3 & 4 & 7 & $5 \%$ \\
\hline Mais de 1000 & 47 & 29 & 76 & $54 \%$ \\
\hline Não está trabalhando & 9 & 0 & 9 & $6 \%$ \\
\hline Total & 83 & 59 & 142 & \\
\hline
\end{tabular}

Fonte: Elaborada pelos autores (2020).

Para efeito de análise dos dados, inicialmente foi utilizada uma abordagem qualitativa, uma vez que se desejava compreender e explicar a dinâmica das relações sociais, sem preocupação com a quantificação dos dados (Silveira \& Córdova, 2009). Para que fosse possível atribuir valores
90,4\% de participantes válidos. Observou-se ligeiro predomínio de participantes que atuam com metodologias Tradicionais, sendo a maior parte composta por gerentes de projetos com muito conhecimento em metodologias de gestão, mais de 10 anos de atuação na área e trabalhando em empresas com mais de 1000 funcionários. A Tabela 1 apresenta em detalhes tais características.

\begin{tabular}{lcccc}
\hline Tempo em projetos & Trad. & Ágil & Total & \% \\
\hline Há mais de 10 anos & 46 & 28 & 74 & $52 \%$ \\
De 5 anos a 10 anos & 19 & 21 & 40 & $28 \%$ \\
De 3 anos a 5 anos & 8 & 5 & 13 & $9 \%$ \\
De 1 ano a 3 anos & 7 & 3 & 10 & $7 \%$ \\
Menos de 1 ano & 3 & 2 & 5 & $4 \%$ \\
\hline Total & $\mathbf{8 3}$ & $\mathbf{5 9}$ & $\mathbf{1 4 2}$ & \\
\hline & & & & \\
& & & & \\
\hline Função & Trad. & Ágil & Total & \% \\
\hline Gerente de Projeto & 36 & 24 & 60 & $42 \%$ \\
Membro de Equipe & 7 & 4 & 11 & $8 \%$ \\
Scrum Master & 0 & 4 & 4 & $3 \%$ \\
Outros & 6 & 5 & 11 & $8 \%$ \\
Consultor & 8 & 6 & 14 & $10 \%$ \\
Agile Coach & 0 & 3 & 3 & $2 \%$ \\
Product Owner & 5 & 6 & 11 & $8 \%$ \\
Instrutor & 1 & 0 & 1 & $1 \%$ \\
Membro Escritório & 6 & 0 & 6 & $4 \%$ \\
de Projetos & & & & \\
Gerente de Portfolio & 7 & 6 & 13 & $9 \%$ \\
Gerente de Programa & 7 & 1 & 8 & $6 \%$ \\
\hline Total & $\mathbf{8 3}$ & $\mathbf{5 9}$ & $\mathbf{1 4 2}$ & \\
\hline
\end{tabular}

e criar uma ordenação de notas recebidas para cada uma das competências analisadas pela escala Likert de cinco pontos, foram atribuídos valores de 1 a 5 às respostas individuais dos participantes. Quanto maior a importância percebida, maior a pontuação recebida. Após a transformação dos graus da escala Likert em 
Perides, M. P. N., Barrote, E. B., \& Sbragia R. (2021, Ed. Esp. jan./abr.). As competências de gestores de projetos que atuam com métodos ágeis e tradicionais: um estudo comparativo

valores ordinais, cada competência teve seu valor somado, consolidando as respostas dos participantes para cada uma delas. Como os resultados encontrados não foram conclusivos, decidiu-se utilizar uma abordagem quantitativa através de métodos paramétricos e não paramétricos. Os métodos não paramétricos buscam analisar a existência de tendências entre os grupos analisados (Gibbons \& Chakraborti, 2011). Para isso, foi escolhido o método de coeficiente de correlação de postos de Kendall, que é muito utilizado nas ciências comportamentais e mede a correlação entre rankings ordenados por posições (Kendall, 1942).

Já as técnicas paramétricas foram utilizadas a fim de verificar se existiam diferenças significativas entre os grupos da amostra através de dois tipos de análises: de perfis dos grupos e de correspondência. A análise de correspondência teve como objetivo descrever graficamente os dados dispostos em tabelas de contingência, de tal forma a representar o padrão de associação entre variáveis. Trata-se, portanto, de uma técnica de ordenação multivariada, usada para criar agrupamentos (Sieber, Petrini, \& Greenacre, 1998). Já a análise de perfis buscou determinar a semelhança de perfis (Hardle \& Simar, 2003) e se havia coincidência entre suas variações.

\section{Apresentação e discussão dos resultados}

Esta seção apresenta e discute os resultados obtidos na pesquisa de campo, tanto por meio da análise qualitativa, como das análises quantitativas com estatísticas não paramétricas e paramétricas.

\subsection{Análise qualitativa}

As competências foram ordenadas de acordo com a pontuação total recebida na escala Likert e as cinco competências com maior pontuação foram destacadas, conforme mostra o Quadro 3.

Quadro 3 - Competências consideradas mais importantes de acordo com a escala Likert

\begin{tabular}{|l|l|l|l|}
\hline \multicolumn{1}{|c|}{ Ágil } & \multicolumn{1}{|c|}{ Tradicional } & \multicolumn{1}{|c|}{ Total } \\
\hline $\mathbf{1}$ & Estratégia & Comunicação Pessoal & $\begin{array}{l}\text { Integridade e Confiabilidade } \\
\text { Pessoal }\end{array}$ \\
\hline $\mathbf{2}$ & Trabalho em Equipe & $\begin{array}{l}\text { Integridade e Confiabilidade } \\
\text { Pessoal }\end{array}$ & Comunicação Pessoal \\
\hline $\mathbf{3}$ & $\begin{array}{l}\text { Integridade e Confiabilidade } \\
\text { Pessoal }\end{array}$ & $\begin{array}{l}\text { Trabalho em Equipe } \\
\text { Celacionamentos e }\end{array}$ & Trabalho em Equipe \\
\hline $\mathbf{4}$ & $\begin{array}{l}\text { Comunicação Pessoal } \\
\text { Engajamento }\end{array}$ & Estratégia \\
\hline $\mathbf{5}$ & $\begin{array}{l}\text { Relacionamentos e } \\
\text { Engajamento }\end{array}$ & Estratégia & Relacionamentos e \\
\hline
\end{tabular}

Fonte: Elaborado pelos autores (2020). 
Perides, M. P. N., Barrote, E. B., \& Sbragia R. (2021, Ed. Esp. jan./abr.). As competências de gestores de projetos que atuam com métodos ágeis e tradicionais: um estudo comparativo

Como pode ser observado no Quadro 3, as cinco competências consideradas mais importantes pelas equipes que atuam tanto com projetos Tradicionais, como com projetos Ágeis, são as mesmas, mas aparecem em ordem diferente. É interessante notar que a competência que aparece em primeiro lugar nessa análise, Integridade e Confiabilidade Pessoal, não aparece em nenhum dos estudos anteriores, como Cheng et al. (2005) e Stevenson e Starkweather (2010). É possível que, por estar relacionada a valores éticos, essa seja uma característica específica de países com frequentes relatos de casos associados à ausência desses valores, tais como corrupção e superfaturamento. Todavia, não há evidências neste estudo que permitam comprovar essa suposição.

Já as competências Comunicação Pessoal e Trabalho em Equipe, que aparecem respectivamente em $2^{\circ}$ e $3^{\circ}$ lugares, encontram suporte em diversos autores (Boehm \& Turner, 2005; Cheng et al., 2005; Nerur et al., 2005; PMI, 2016; Stevenson \& Starkweather, 2010).
No trabalho de Stevenson e Starkweather (2010) é ressaltado que em projetos de TI, habilidades referentes à Comunicação aparecem em primeiro lugar. Cheng et al. (2005) destacam a importância da Comunicação, na competência identificada pelos autores como Impacto e Influência. Trabalho em Equipe também aparece com destaque no índice de competências mais importantes do gerente de projetos, analisadas por tais autores.

Em seguida foi feita a tabulação das cinco competências que aparecem como mais importantes para os respondentes. Para tal, foi feita uma pergunta onde todas as competências foram apresentadas em conjunto, para que o participante pudesse selecionar apenas as três consideradas mais importantes. Surpreendentemente, as respostas mostraram um conteúdo diferente da análise anterior, como pode ser visto no Quadro 4.

Quadro 4 - Competências consideradas mais importantes de acordo com a seleção das três competências mais relevantes para os respondentes

\begin{tabular}{|c|c|c|c|}
\hline & Ágil & Tradicional & Total \\
\hline 1 & Estratégia & Trabalho em Equipe & Trabalho em Equipe \\
\hline 2 & Trabalho em Equipe & Liderança & Liderança \\
\hline 3 & Liderança & Estratégia & Estratégia \\
\hline 4 & Escopo & Orientação para Resultados & Escopo \\
\hline 5 & Comunicação Pessoal & Governança, Estrutura e Processos & Comunicação Pessoal \\
\hline
\end{tabular}

Fonte: Elaborado pelos autores (2020). 
Perides, M. P. N., Barrote, E. B., \& Sbragia R. (2021, Ed. Esp. jan./abr.). As competências de gestores de projetos que atuam com métodos ágeis e tradicionais: um estudo comparativo

Embora competências como Trabalho em Equipe e Estratégia ainda apareçam com grande destaque, Liderança, que não aparecia entre as cinco competências mais importantes na análise inicial, passa a ter uma importância bem mais relevante quando os respondentes selecionam apenas as três competências consideradas mais importantes. Liderança também aparece no trabalho de Cheng et al. (2005) como uma competência crítica. Já Estratégia, definida como a capacidade de alinhar equipe com a missão e propósito do projeto, não é destacada em estudos sobre competências mais importantes para o gerente de projetos, mas aparece com destaque na literatura sobre abordagens Ágeis, sendo considerada essencial para liderar nesse ambiente (Boehm \& Turner, 2005; Denning, 2016a; Nerur et al., 2005). Chama a atenção o fato de Escopo aparecer com grande destaque para equipes Ágeis, o que poderia estar associado à identificação da liderança com a função do Representante do Cliente ou Dono do Produto (Product Owner). Já na análise das respostas das equipes que usam abordagens Tradicionais aparecem: Orientação a Resultados e Governança, Estrutura e Processos, que são competências associadas à figura tradicional do gerente de projetos. Por sua vez, Comunicação Pessoal que aparecia em primeiro lugar para indivíduos que usam métodos Tradicionais, deixa de constar da relação válida para os que usam métodos Ágeis.

Em seguida, investigou-se se a senioridade poderia influenciar o resultado. Para essa análise os participantes foram divididos em dois grupos: a) seniores: respondentes com mais de 10 anos de atuação em projetos; e b) juniores: respondentes com menos de 10 anos de atuação em projetos. Os resultados encontrados estão no Quadro 5. 
Perides, M. P. N., Barrote, E. B., \& Sbragia R. (2021, Ed. Esp. jan./abr.). As competências de gestores de projetos que atuam com métodos ágeis e tradicionais: um estudo comparativo

Quadro 5 - Competências mais importantes de acordo com a escala Likert, considerando o grau de senioridade do respondente

\begin{tabular}{|c|c|c|c|}
\hline \multicolumn{2}{|r|}{$\begin{array}{l}\text { Seniores - Ágil } \\
\text { (28 respondentes) }\end{array}$} & \multirow{2}{*}{$\begin{array}{l}\begin{array}{c}\text { Seniores - Tradicional } \\
\text { (46 respondentes) }\end{array} \\
\text { Comunicação Pessoal }\end{array}$} & \multirow{2}{*}{$\begin{array}{l}\text { Seniores - Total } \\
\qquad \begin{array}{l}\text { (74 respondentes) } \\
\text { Integridade e Confiabilidade } \\
\text { Pessoal }\end{array}\end{array}$} \\
\hline 1 & $\begin{array}{l}\text { Integridade e Confiabilidade } \\
\text { Pessoal }\end{array}$ & & \\
\hline 2 & Estratégia & $\begin{array}{l}\text { Integridade e Confiabilidade } \\
\text { Pessoal }\end{array}$ & Comunicação Pessoal \\
\hline 3 & Trabalho em Equipe & Conflito e Crise & Estratégia \\
\hline 4 & Comunicação Pessoal & Estratégia & Conflito e Crise \\
\hline 5 & $\begin{array}{l}\text { Relacionamentos e } \\
\text { Engajamento }\end{array}$ & $\begin{array}{l}\text { Relacionamentos e } \\
\text { Engajamento }\end{array}$ & $\begin{array}{l}\text { Relacionamentos e } \\
\text { Engajamento }\end{array}$ \\
\hline & $\begin{array}{l}\text { Juniores -Ágil } \\
\text { (31 respondentes) }\end{array}$ & $\begin{array}{l}\text { Juniores - Tradicional } \\
\text { (37 respondentes) }\end{array}$ & $\begin{array}{l}\text { Juniores - Total } \\
\text { (68 respondentes) }\end{array}$ \\
\hline 1 & Estratégia & Comunicação Pessoal & Comunicação Pessoal \\
\hline 2 & Trabalho em Equipe & $\begin{array}{l}\text { Integridade e Confiabilidade } \\
\text { Pessoal }\end{array}$ & Trabalho em Equipe \\
\hline 3 & Comunicação Pessoal & Trabalho em Equipe & $\begin{array}{l}\text { Integridade e Confiabilidade } \\
\text { Pessoal }\end{array}$ \\
\hline 4 & $\begin{array}{l}\text { Integridade e Confiabilidade } \\
\text { Pessoal }\end{array}$ & $\begin{array}{l}\text { Relacionamentos e } \\
\text { Engajamento }\end{array}$ & Estratégia \\
\hline 5 & Partes Interessadas & Estratégia & $\begin{array}{l}\text { Relacionamentos e } \\
\text { Engajamento }\end{array}$ \\
\hline
\end{tabular}

Fonte: Elaborado pelos autores (2020).

Analisando os dados do Quadro 5 é possível perceber que as competências consideradas mais importantes têm pouca variação quando se observa a senioridade do profissional. Integridade, Confiabilidade, Comunicação Pessoal, Estratégia, Relacionamento e Engajamento, são competências importantes, independente da senioridade. Já Trabalho em Equipe aparece com destaque para profissionais mais juniores, talvez devido ao fato de esses profissionais dependerem mais do apoio dos colegas. Já Conflito e Crise é considerada importante para o grupo mais sênior, que provavelmente já vivenciou mais situações conflituosas, valorizando o líder que saiba gerenciar conflitos adequadamente. Vale ressaltar que essa competência não aparece com destaque em nenhum dos autores pesquisados.

O próximo passo foi analisar se existiam diferenças entre $o$ resultado apresentado por profissionais que atuam em grandes organizações e os que trabalham em empresas menores. Para essa análise, os respondentes também foram divididos em dois grupos: a) profissionais que trabalham em empresas com mais de 1000 funcionários; e b) profissionais que trabalham em empresas com 
Perides, M. P. N., Barrote, E. B., \& Sbragia R. (2021, Ed. Esp. jan./abr.). As competências de gestores de projetos que atuam com métodos ágeis e tradicionais: um estudo comparativo

menos de 1000 funcionários. Os resultados podem ser vistos no Quadro 6. Cabe mencionar que os profissionais que não estavam trabalhando no momento da pesquisa (9 respondentes) foram desconsiderados nesta análise.

Quadro 6 - Competências mais importantes de acordo com a escala Likert, considerando o porte da empresa

\begin{tabular}{|c|c|c|c|}
\hline \multirow{2}{*}{\multicolumn{2}{|c|}{$\begin{array}{l}\text { Mais de } 1000 \text { funcionários - Ágil } \\
\text { (29 respondentes) }\end{array}$}} & \multirow{3}{*}{$\begin{array}{l}\text { Mais de } 1000 \text { funcionários - } \\
\text { Tradicional } \\
\text { (47 respondentes) } \\
\text { Integridade e Confiabilidade } \\
\text { Pessoal }\end{array}$} & \multirow{3}{*}{$\begin{array}{c}\text { Mais de } 1000 \text { funcionários - } \\
\text { Total } \\
\text { (76 respondentes) } \\
\text { Comunicação Pessoal }\end{array}$} \\
\hline & & & \\
\hline 1 & Estratégia & & \\
\hline 2 & Trabalho em Equipe & Comunicação Pessoal & $\begin{array}{l}\text { Integridade e Confiabilidade } \\
\text { Pessoal }\end{array}$ \\
\hline 3 & Liderança & Relacionamentos e Engajamento & Estratégia \\
\hline 4 & Comunicação Pessoal & Estratégia & Trabalho em Equipe \\
\hline 5 & $\begin{array}{l}\text { Integridade e Confiabilidade } \\
\text { Pessoal }\end{array}$ & Trabalho em Equipe & Relacionamentos e Engajamento \\
\hline \multicolumn{2}{|c|}{$\begin{array}{l}\text { Menos de } 1000 \text { funcionários - Ágil } \\
\text { (30 respondentes) }\end{array}$} & $\begin{array}{c}\text { Menos de } 1000 \text { funcionários - } \\
\text { Cascata } \\
\text { (27 respondentes) }\end{array}$ & $\begin{array}{c}\text { Menos de } 1000 \text { funcionários - } \\
\text { Total } \\
\text { (57 respondentes) }\end{array}$ \\
\hline 1 & $\begin{array}{l}\text { Integridade e Confiabilidade } \\
\text { Pessoal }\end{array}$ & Conflito e Crise & $\begin{array}{l}\text { Integridade e Confiabilidade } \\
\text { Pessoal }\end{array}$ \\
\hline 2 & Comunicação Pessoal & Escopo & Trabalho em Equipe \\
\hline 3 & Trabalho em Equipe & Estratégia & Comunicação Pessoal \\
\hline 4 & Estratégia & $\begin{array}{l}\text { Integridade e Confiabilidade } \\
\text { Pessoal }\end{array}$ & Escopo \\
\hline 5 & Escopo & Trabalho em Equipe & Conflito e Crise \\
\hline
\end{tabular}

Fonte: Elaborado pelos autores (2020).

Como pode ser visto no Quadro 6, profissionais que trabalham em grandes organizações valorizam líderes que tenham as competências de Comunicação, Integridade e Confiabilidade Pessoal, assim como valorizam Estratégia e Trabalho em Equipe. No entanto, em empresas menores, a Estratégia não aparece entre as cinco competências mais importantes, provavelmente por ser mais fácil manter o alinhamento quando há maior proximidade entre a cúpula e a base. Já Escopo, surge como uma competência importante para profissionais que atuam em empresas com menos de 1000 funcionários, evidenciando uma provável dificuldade dessas organizações em delimitar o trabalho que deve ser feito, independente da metodologia adotada.

Não obstante as análises efetuadas, os dados resultantes não permitem quaisquer 
Perides, M. P. N., Barrote, E. B., \& Sbragia R. (2021, Ed. Esp. jan./abr.). As competências de gestores de projetos que atuam com métodos ágeis e tradicionais: um estudo comparativo

conclusões sobre as semelhanças e diferenças entre as competências consideradas mais e menos importantes para cada um dos grupos analisados. De fato, segundo Silveira e Córdova (2009), a pesquisa qualitativa não tem a intenção de estabelecer relações quantitativas, não se preocupando com a quantificação numérica, e sim com a compreensão de um grupo social de uma organização.

\subsection{Análise quantitativa}

Conforme exposto na seção anterior, as análises qualitativas não permitiram uma conclusão sobre as competências estudadas. Partiu-se então para análises estatísticas paramétricas e não paramétricas a fim de investigar se alguma diferenciação poderia ser estabelecida. Os resultados dessas análises são apresentados a seguir.

\subsubsection{Análise Não Paramétrica}

A análise não paramétrica comparou as escolhas feitas pelos dois grupos estudados (Ágil e Tradicional) por meio do coeficiente tau de Kendall (Romdhani, Lakhal-Chaieb, \& Rivest, 2014), utilizando o software SPSS. Segundo Romdhani et al. (2014), a comparação realizada pelo tau de Kendall mede a associação definida como a probabilidade de concordância menos a probabilidade de discordância entre grupos.

Foram feitas duas análises distintas. A primeira análise comparou a ordem de escolha das 28 competências apresentadas individualmente, feitas por cada grupo de acordo com a escala Likert. A segunda análise também avaliou a escolha das 28 competências, mas utilizando a última questão da pesquisa, na qual foram apresentadas todas as competências conjuntamente para que o respondente apontasse apenas as 3 mais importantes.

Os resultados apontaram uma correlação significativa entre os dois grupos para as duas análises, sendo tau da ordem de 0,683 e 0,771 respectivamente, o que denota ordenações semelhantes. Sendo assim, pode-se concluir que não houve diferenças significativas entre a percepção de importância das competências para os profissionais que utilizam as metodologias Ágeis e Tradicionais em nenhuma das duas análises.

\subsubsection{Análises Paramétricas}

A análise paramétrica procura determinar as relações existentes entre os grupos de profissionais ao responderem sobre a importância de cada competência de acordo com a escala Likert. O objetivo dessa análise foi descobrir se houve paralelismo e coincidência entre as respostas dos dois perfis.

O estudo de paralelismo de perfil busca avaliar se os perfis dos dois grupos são similares (paralelos), o que significaria dizer que não há interação entre a resposta dos dois grupos (Hardle \& Simar, 2003). Já a análise de coincidência entre perfis dos respondentes Ágil e Tradicional avalia se os grupos variam de forma coincidente (com o mesmo grau de 
Perides, M. P. N., Barrote, E. B., \& Sbragia R. (2021, Ed. Esp. jan./abr.). As competências de gestores de projetos que atuam com métodos ágeis e tradicionais: um estudo comparativo

variação). O resultado pode ser visto na Figura

2.

Figura 2 - Análise de perfil dos dois grupos respondentes (Ágil e Tradicional)

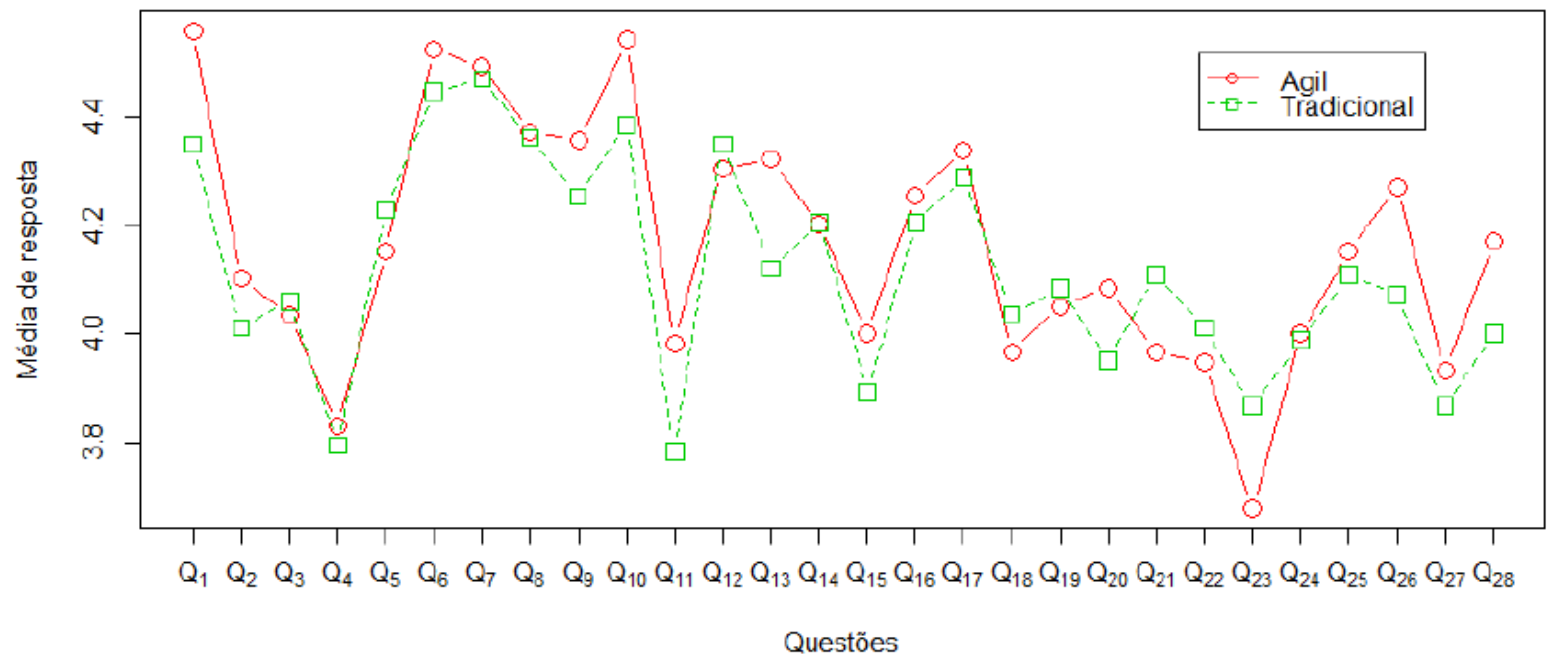

Fonte: Elaborada pelos autores (2020).

Os resultados apontam um p-valor de 0,729 para paralelismo e 0,547 para coincidência entre os perfis, com nível de significância de 5\%. Esse resultado indica que, também por essa análise, não é possível rejeitar a hipótese de que os perfis dos profissionais Ágil e Tradicional sejam semelhantes quando avaliam a relevância de cada competência apresentada individualmente.

Optou-se então por analisar a amostra, buscando determinar se existiam clusters (grupos) relevantes de respondentes. $\mathrm{O}$ agrupamento foi feito com o algoritmo implementado na função daisy do Software R, utilizado para a formação de grupos com base nas variáveis categóricas de identificação do respondente: grau de conhecimento da metodologia utilizada, tipo de metodologia utilizada (Ágil ou Tradicional), função exercida e tamanho da empresa onde trabalha.

$\mathrm{O}$ algoritmo utilizado apresentou três grupos bem definidos. $\mathrm{O}$ primeiro agrupamento teve como característica marcante o fato de todos os profissionais serem provenientes de grandes empresas (com mais de 1000 funcionários), sendo que nessa seleção existiam profissionais tanto usuários da metodologia Ágil, quanto da metodologia Tradicional. A maioria dos integrantes desse grupo tinha grande conhecimento sobre metodologias e mais de 10 anos de experiência com gestão de projetos.

O segundo cluster formado contava com profissionais provenientes de diferentes portes de empresas, mas sua característica mais acentuada era a predominância de profissionais que utilizavam metodologias Tradicionais. Apesar de contar com profissionais de 
Perides, M. P. N., Barrote, E. B., \& Sbragia R. (2021, Ed. Esp. jan./abr.). As competências de gestores de projetos que atuam com métodos ágeis e tradicionais: um estudo comparativo

diferentes funções, havia uma grande concentração na função de gerente de projetos. Por fim, o último cluster era formado principalmente por profissionais provenientes de pequenas empresas, sendo esses usuários apenas de metodologias Ágil.

A partir da formação desses novos agrupamentos, para que fosse possível determinar a existência ou não de paralelismo e coincidência entre perfis, foi refeita a análise das respostas quanto à importância das 28 competências avaliadas pela escala Likert de 5 pontos. O resultado encontrado pode ser visto na Figura 3.

Figura 3 - Análise do perfil dos clusters

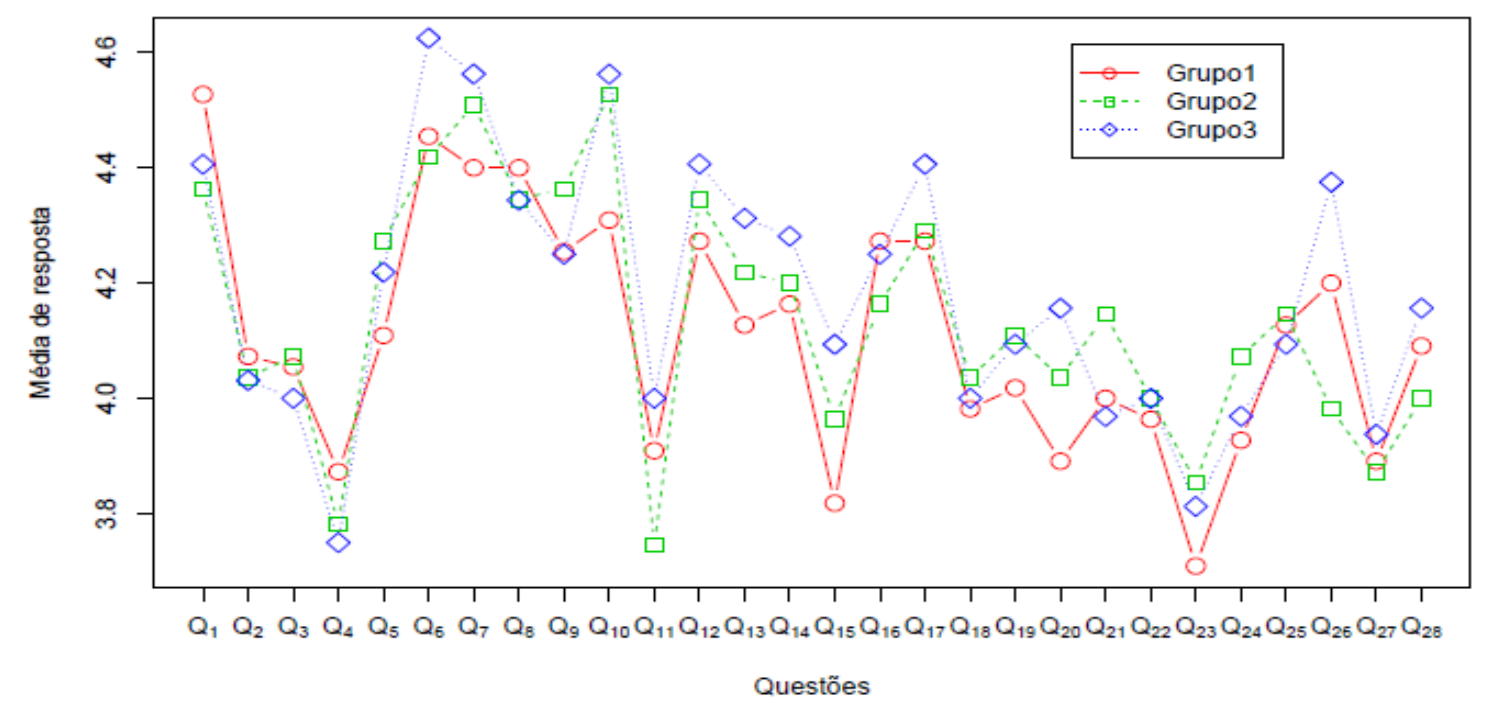

Fonte: Elaborada pelos autores (2020).

Os clusters foram então tomados dois a dois, com o intuito de determinar se existiam diferenças estatísticas relevantes entre os

Tabela 2 - P-valor encontrado para os clusters analisados 2 a 2

\begin{tabular}{lcc}
\hline & Paralelismo & Coincidência \\
\hline Grupo 1 x Grupo 2 & 0,18 & 0,754 \\
Grupo 1 x Grupo 3 & 0,947 & 0,777 \\
Grupo 2 x Grupo 3 & 0,921 & 0,773 \\
\hline
\end{tabular}

Fonte: Elaborada pelos autores (2020). mesmos. Os resultados estão apresentados na Tabela 2. 
Perides, M. P. N., Barrote, E. B., \& Sbragia R. (2021, Ed. Esp. jan./abr.). As competências de gestores de projetos que atuam com métodos ágeis e tradicionais: um estudo comparativo

Não foram encontradas evidências amostrais suficientes para concluir que há diferença entre o perfil de respostas para os grupos formados por meio da análise de agrupamentos. Uma análise final foi então realizada utilizando a última questão da pesquisa, que apresentava todas as competências em conjunto e solicitava ao profissional que escolhesse, dentre todas, as três mais importantes. Assim, para verificar a existência de alguma associação entre as respostas e as variáveis em estudo (metodologia utilizada, tamanho da empresa e experiência profissional) foi utilizada a técnica de análise de correspondência. As três variáveis consideradas foram agrupadas conforme mostra o Quadro 7.

Quadro 7 - Grupos de variáveis para análise de correspondência

\begin{tabular}{|c|l|}
\hline Grupo & \\
\hline $\mathrm{AgSe}>$ & Metodologia Ágil, profissional sênior, empresa grande. \\
\hline $\mathrm{AgSe}<$ & Metodologia Ágil, profissional sênior, empresa pequena. \\
\hline $\mathrm{AgJu}>$ & Metodologia Ágil, profissional júnior, empresa grande. \\
\hline $\mathrm{AgJu}<$ & Metodologia Ágil, profissional júnior, empresa pequena. \\
\hline $\mathrm{TrSe}>$ & Metodologia Tradicional, profissional sênior, empresa grande. \\
\hline $\mathrm{TrSe}<$ & Metodologia Tradicional, profissional sênior, empresa pequena. \\
\hline $\mathrm{TrJu}>$ & Metodologia Tradicional, profissional júnior, empresa grande. \\
\hline $\mathrm{TrJu}<$ & Metodologia Tradicional, profissional júnior, empresa pequena. \\
\hline Tis & \\
\hline
\end{tabular}

Fonte: Elaborado pelos autores (2020).

Os resultados da análise de correspondência a partir dos agrupamentos são mostrados na Figura 4. 
Perides, M. P. N., Barrote, E. B., \& Sbragia R. (2021, Ed. Esp. jan./abr.). As competências de gestores de projetos que atuam com métodos ágeis e tradicionais: um estudo comparativo

Figura 4 - Análise de Correspondência

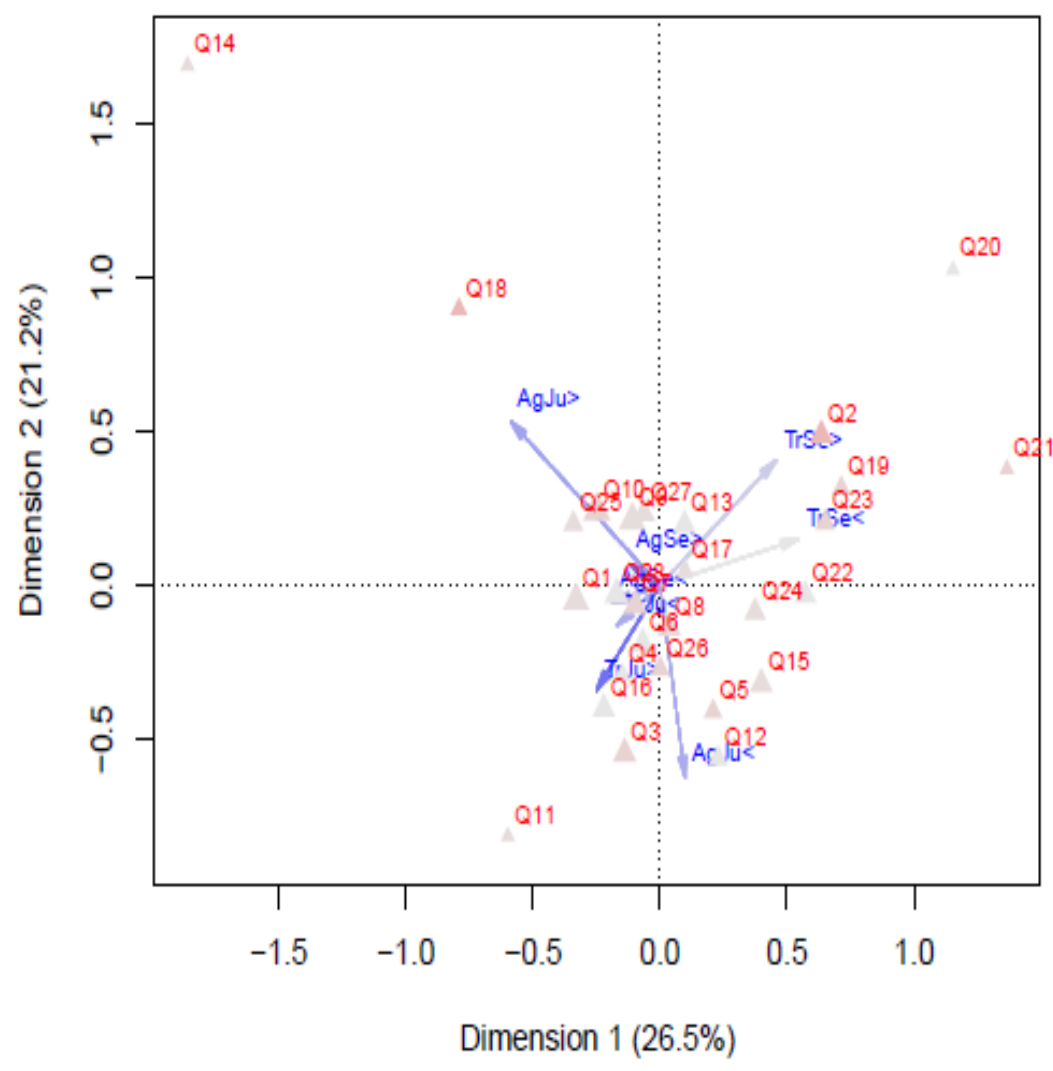

\begin{tabular}{|c|c|}
\hline Q1 & Estratégia \\
\hline Q2 & $\begin{array}{l}\text { Governança, Estrutura e } \\
\text { Processos }\end{array}$ \\
\hline Q3 & $\begin{array}{l}\text { Cultura e Valores } \\
\end{array}$ \\
\hline Q4 & Poder e interesse \\
\hline Q5 & $\begin{array}{c}\text { Conformidade, Normas e } \\
\text { Regulamentos }\end{array}$ \\
\hline Q6 & $\begin{array}{c}\text { Integridade e Confiabilidade } \\
\text { Pessoal }\end{array}$ \\
\hline Q7 & Comunicação Pessoal \\
\hline Q8 & $\begin{array}{l}\text { Relacionamentos e } \\
\text { Engajamento }\end{array}$ \\
\hline Q9 & Liderança \\
\hline Q10 & Trabalho e1 \\
\hline Q11 & Desenvoltura \\
\hline Q12 & Conflito e Crise \\
\hline Q13 & Negociação \\
\hline Q14 & Desenho do Projeto \\
\hline Q15 & $\begin{array}{l}\text { Orientação para } \\
\text { Resultados. }\end{array}$ \\
\hline Q16 & $\begin{array}{l}\text { Organização e } \\
\text { Comunicação }\end{array}$ \\
\hline Q17 & Tempo \\
\hline Q18 & Qualidade \\
\hline Q19 & Custos \\
\hline Q20 & Recursos \\
\hline $\mathbf{Q 2 1}$ & Aquisição e Parcerias \\
\hline $\mathbf{Q 2 2}$ & Planejar e Controlar \\
\hline Q23 & Riscos e Oportumidades \\
\hline Q24 & Stakeholders \\
\hline Q25 & Mudança e Transformação \\
\hline Q26 & Autorreflexão e autogestão \\
\hline Q27 & $\begin{array}{c}\text { Requisitos, Objetivos e } \\
\text { Beneficios }\end{array}$ \\
\hline $\mathbf{0 2 8}$ & Escopo \\
\hline
\end{tabular}

Fonte: Elaborada pelos autores (2020).

A partir da Figura 4 é possível notar que o grupo AgJu> (metodologia Ágil, profissional júnior, empresa grande) tende a considerar as competências de Qualidade e Desenho do Projetos uma das três mais importantes, ou seja, esse perfil valoriza competências mais técnicas. O grupo TrSe> (metodologia Tradicional, profissional sênior, empresa grande), por sua vez, considera relevante as competências Governança e Recursos. Uma vez que tais competências não foram destacadas pelos profissionais juniores, admite-se ser essa uma preocupação dos profissionais mais seniores. Já o grupo TrJu> (metodologia Tradicional, profissional júnior, empresa grande) atribui maior importância à competência Desenvoltura, provavelmente em razão da dificuldade de defender os interesses do projeto em organizações grandes e tradicionais. Nota-se ainda uma nuvem de pontos próximo ao centro $(0,0)$, indicando que o perfil de resposta dos demais grupos é bastante similar com relação às três competências mais importantes.

Vale ressaltar que apenas quatro indivíduos julgaram a competência Qualidade como uma das três mais importantes, e um indivíduo apenas selecionou a competência Desenho do Projeto. Dessa forma, como há uma baixa frequência de resposta para essas 
competências, não há evidências suficientes para dizer que essa tendência é, de fato, existente. Também, essa análise indica que não há evidências de existência de diferença entre o perfil de resposta dos indivíduos para as três competências mais importantes considerando as três variáveis em estudo (metodologia utilizada, tamanho da empresa e experiência do profissional).

Assim, com base nas diversas análises realizadas, pode-se concluir que embora a análise qualitativa tenha mostrado algumas diferenças entre as competências consideradas mais importantes para gestores de projetos que trabalham com metodologias Tradicionais e aqueles utilizando metodologias Ágeis, as análises quantitativas mostram que não há evidências suficientes para suportar tal diferenciação. Essa afirmação também é verdadeira quando considerada a senioridade e o tamanho da empresa em que o profissional trabalha. $\mathrm{O}$ resultado encontrado nesta pesquisa é similar ao de Garcia e Russo (2019), que também não identificaram diferenças significativas entre a influência de uma liderança que atua com método Tradicional ou Ágil no desempenho da equipe.

\section{Conclusões e considerações finais}

O objetivo deste estudo foi objetivo comparar as competências consideradas mais importantes para um gestor de projetos que atua predominantemente com metodologias Tradicionais e o líder de projetos que utiliza abordagens Ágeis, de acordo com os profissionais que atuam com essas abordagens.

A análise qualitativa mostrou que as competências mais valorizadas pelos profissionais (quando utilizada a escala Likert de 5 pontos) são: Integridade e Confiabilidade Pessoal, Comunicação Pessoal, Trabalho em Equipe, Estratégia e Relacionamentos e Engajamento, nessa ordem. No entanto, quando os respondentes foram solicitados a selecionar apenas as três competências consideradas mais importantes, as mais citadas foram: Trabalho em Equipe, Liderança, Estratégia, Escopo e Comunicação Pessoal.

As análises estatísticas, por sua vez, não permitiram afirmar que há diferenças significativas entre a percepção de importância das competências nas escolhas feitas pelos profissionais que trabalham com metodologias Ágeis e Tradicionais. Talvez um ponto relevante a mencionar seja o fato de que, no ambiente das metodologias Ágeis, as competências humanas, de acordo com a seleção das três mais importantes para os respondentes, aparecem em maior destaque do que as demais, notadamente Trabalho em Equipe, Liderança e Comunicação pessoal, evidenciando a importância desses requerimentos na figura do Líder de Projetos.

Todos esses resultados inconclusivos evidentemente geram indagações. Müller e Turner (2010) identificaram diferenças nas competências mais importantes para o gerente de projetos de acordo com o tipo de aplicação, a complexidade, importância e tipo de contrato 
do projeto. É possível que esses fatores sejam mais determinantes na definição das competências adequadas ao gerente de projetos do que o tipo de metodologia de gerenciamento utilizada. Também é possível que o fato de as abordagens Ágeis ainda serem recentes no mercado e a maioria das organizações adotar uma abordagem híbrida, adaptando aspectos das metodologias Ágeis e Tradicionais, de acordo com sua realidade e necessidade, tenha influenciado nesse resultado.

A similaridade das respostas apresentadas entre os profissionais que trabalham com métodos Ágeis e os que trabalham com abordagens mais tradicionais nos levam a questionar se, ao adotarem abordagens Ágeis, as organizações estão conseguindo criar uma cultura organizacional que lhes permitam explorar o potencial desse novo modelo de gestão. A maioria dos respondentes deste estudo trabalhava em grandes organizações (mais de 1000 profissionais), onde relações de poder através da hierarquia ainda são preservadas. Também é possível que, pelo fato de a amostra ser composta majoritariamente por profissionais que atuam há muito tempo com projetos, parte deles ainda tenha uma percepção de liderança alinhada com ambientes mais tradicionais, mesmo declarando trabalhar com abordagens Ágeis.

Há de se reconhecer que, embora o questionário tenha sido largamente divulgado nas redes sociais, a quantidade de respostas válidas recebidas (142 questionários válidos) foi claramente uma das limitações deste estudo. Outra limitação pode ser atribuída à amostra empregada, por conveniência, que acabou por apresentar uma grande parcela de profissionais seniores e que trabalham em grandes organizações, o que não necessariamente reflete a realidade dessa população.

Em estudos futuros, com vistas a uma investigação mais profunda a respeito das relações aqui investigadas, sugere-se que maior precisão seja conferida às medições, bem como a utilização de amostras maiores e mais representativas dessa comunidade. Sugere-se também, o uso de entrevistas e/ou questionários pessoalmente aplicados, o que permitirá um aprofundamento nos motivos dessas escolhas por parte dos respondentes. Abre-se aqui, portanto, uma importante linha de pesquisa, uma vez que a adoção de métodos Ágeis por grande parte das organizações requer uma nova maneira de agir a pensar e, consequentemente, líderes que consigam, mesmo sem posições formais, conduzir suas equipes nesse novo cenário entregando constantemente valor a seus clientes.

\section{Referências}

Ambler, S. W., \& Lines, M. (2020). Choose your WOW! A Disciplined Agile Delivery Handbook for Optimizing Your Way of Working. Pennsylvania, EUA: Project Management Institute, Inc.

Barlow, J., Giboney, J., Keith, M. J., Wilson, D., Schuetzler, R., Lowry, P. B., \& Vance, A. (2012). Overview and Guidance on Agile Development in Large Organizations. 
Perides, M. P. N., Barrote, E. B., \& Sbragia R. (2021, Ed. Esp. jan./abr.). As competências de gestores de projetos que atuam com métodos ágeis e tradicionais: um estudo comparativo

Communications of the Association for Information Systems, 29(2), 25-44. doi: 10.2139/ssrn.1909431

Beck, K., Beedle, M., Bennekum, A. van, Cockburn, A., Cunningham, W., Fowler, M., ... Thomas, D. (2001). The Agile Manifesto. Recuperado de: www.agilemanifesto.org. Acesso em 18/abr/2019

Boehm, B., \& Turner, R. (2005). Management challenges to implementing agile processes in traditional development organizations. IEEE Software, 22(5), 30-39. doi: 10.1109/MS.2005.129

Boyatzis, R. E. (1982). Competent manager: a model for effective performance. New York: Wiley \& Sons.

Cheng, M.-I., Dainty, A. R. J., \& Moore, D. R. (2005). What makes a good project manager? Human Resource Management Journal, 15(1), 25-37. doi: 10.1111/j.17488583.2005.tb00138.x

Chipulu, M., Neoh, J. G., Ojiako, U., \& Williams, T. (2013). A Multidimensional Analysis of Project Manager Competences. IEEE Transactions On Engineering Management, 60(3), 506-517. doi:10.1109/TEM.2012.2215330

Cockburn, A., \& Highsmith, J. (2001). Agile Software Development: The People Factor. Computer, 34(11), 131-133. doi: $10.1109 / 2.963450$

Cram, W. A., \& Marabelli, M. (2018). Have your cake and eat it too? Simultaneously pursuing the knowledge-sharing benefits of agile and traditional development approaches. Information and Management, 55(3), 322-339. doi: 10.1016/j.im.2017.08.005

Denning, S. (2016a). How to make the whole organization "Agile". Strategy \& Leadership, 44(4), 10-17. https://doi.org/10.1108/SL-09-2015-0074

Denning, S. (2016b). Understanding the three laws of Agile. Strategy \& Leadership, 44(6), 3-8. doi: 10.1108/SL-09-2016-0074

Denning, S. (2019). Lessons learned from mapping successful and unsuccessful agile transformation journeys. Strategy \& Leadership, 47(4), 3-11. doi: 10.1108/SL04-2019-0052

Dutra, J. S. (2017). Competências: conceitos, instrumentos e experiências ( $2 \mathrm{a}$ ed.). Sao Paulo: Atlas.

Dybå, T., \& Dingsøyr, T. (2008). Empirical studies of agile software development: A systematic review. Information and Software Technology, 50(9-10), 833-859. doi: 10.1016/j.infsof.2008.01.006

Erickson, J., Lyytinen, K., \& Siau, K. (2005). Agile Modeling, Agile software Development, and extreme programming: the state of research. Journal of Database Management, 16(4), 88-100. doi: $10.4018 / \mathrm{jdm} .2005100105$

Fleury, A., \& Fleury, M. T. (2000). Estratégias Empresariais e Formação de Competências: Um Quebra-cabeça Caleidoscópico da Indústria Brasileira. São Paulo: Atlas.

Freitas, H., Oliveira, M., Saccol, A. Z., \& Moscarola, J. (2000). O Método de Pesquisa Survey. Revista de Administração, 35(3), 105-112.

Garcia, F. A. Z., \& Russo, R. F. S. M. (2019). Leadership and performance of the software development team: Influence of the type of project management. Revista Brasileira de Gestao de Negocios, 21(4), 970-1005. doi: 10.7819/rbgn.v21i5.4028

Gerster, D., Dremel, C., Brenner, W., \& Kelker, P. (2020). How Enterprises Adopt Agile Forms of Organizational Design: A Multiple- Case Study. The DATA BASE for Advances in Information Systems, 51(1), 84-103. doi: 10.1145/3380799.3380807

Gibbons, J. D., \& Chakraborti, S. (2011). Nonparametric Statistical Inference (5th ed.). Boca Raton, FL EUA: Chapman \& 
Perides, M. P. N., Barrote, E. B., \& Sbragia R. (2021, Ed. Esp. jan./abr.). As competências de gestores de projetos que atuam com métodos ágeis e tradicionais: um estudo comparativo

Hall.

Gill, A. Q., Henderson-Sellers, B., \& Niazi, M. (2018). Scaling for agility: A reference model for hybrid traditional-agile software development methodologies. Information Systems Frontiers, 20, 315-341. doi: 10.1007/s10796-016-9672-8

Hardle, W., \& Simar, L. (2003). Applied Multivariate Statistical Analysis. New York, EUA: Springer-Verlag Berlin Heidelberg.

IPMA - International Project Management Association. (2015). Individual Competence Baseline for Project, Programme and Portfolio Management (4th ed.). Zurich: International Project Management Association. Recuperado de: https://www.pma.at/files/downloads/440/ip maicb4.pdf. Acesso em 18/abr/2019

IPMA - International Project Management Association. (2018). IPMA Reference Guide ICB4 in an Agile World (Version 2.2). Zurich: International Project Management Association. Recuperado de: https://www.studocu.com/pt/document/instit uto-superior-tecnico/mooc-agileleadership/outro/ipma-reference-guide-icb4in-agile-world/8580618/view. Acesso em 17/abr/2019

Kendall, M. G. (1942). Partial Rank Correlation. Biometrika, 32(3-4), 277-283. doi: $10.2307 / 2332130$

Kregel, I., Ogonek, N., \& Matthies, B. (2019). Competency profiles for lean professionals - an international perspective. International Journal of Productivity and Performance Management, 68(2), 423-446. doi: 10.1108/IJPPM-09-2017-0237

Larman, C., \& Basili, V. R. (2003). Iterative and incremental development: A brief history. IEEE Computer Society, 36(6), 4756. doi: 10.1109/MC.2003.1204375

Le Boterf, G. (2003). Desenvolvendo a Competência dos Profissionais (3a ed.). Porto Alegre - RS: Artmed Editora SA.
Loufrani-Fedida, S., \& Missonier, S. (2015). The project manager cannot be a hero anymore! Understanding critical competencies in project-based organizations from a multilevel approach. International Journal of Project Management, 33(6), 1220-1235. doi: 10.1016/j.ijproman.2015.02.010

Matook, S., \& Maruping, L. M. (2014). A competency model for customer representatives in agile software development. MIS Quarterly Executive, 13(2), 77-95.

McClelland, D. C. (1973). Testing for competence rather than for "intelligence." American Psychologist, 28(1), 1-14. doi: 10.1037/h0034092

Müller, R., \& Turner, R. (2010). Leadership competency profiles of successful project managers. International Journal of Project Management, 28(5), 437-448. doi: 10.1016/j.ijproman.2009.09.003

Nerur, S., Mahapatra, R., \& Mangalaraj, G. (2005). Challenges of migrating to Agile methodologies. Communications of the ACM, 48(5), 73-78. doi: $10.1145 / 1060710.1060712$

Noro, G. B., \& Bronzatti, B. (2013). A Influência das Características do Gestor no Sucesso da Gestão de Projetos. Revista de Gestão e Projetos, 4(1), 77-115. doi: 10.5585/gep.v4i1.73

PMI - Project Management Institute. (2016). Guia do Conhecimento em Gerenciamento de Projetos (6a ed.). Pensilvânia, EUA: Project Management Institute, Inc.

PMI - Project Management Institute. (2017a). Guia Ágil. Pensilvânia, EUA: Project Management Institute, Inc.

PMI - Project Management Institute. (2017b). Project Manager Competency Development Framework (3rd ed.). Pensilvânia, EUA: Project Management Institute, Inc.

Rajagopalan, S. (2014). Review of the Myths 
Perides, M. P. N., Barrote, E. B., \& Sbragia R. (2021, Ed. Esp. jan./abr.). As competências de gestores de projetos que atuam com métodos ágeis e tradicionais: um estudo comparativo

on Original Software Development Model. International Journal of Software

Engineering \& Applications, 5(6), 103-111. doi: 10.5121/ijsea.2014.5607

Rigby, D. K., Sutherland, J., \& Takeuchi, H. (2016). Embracing Agile. Harvard Business Review, 94(5), 40-48.

Romdhani, H., Lakhal-Chaieb, L., \& Rivest, L.-P. (2014). An exchangeable Kendall's tau for clustered data. The Canadian Journal of Statistics, 42(3), 384-403. doi: $10.1002 /$ cjs. 11223

Seymour, T., \& Hussein, S. (2014). The History Of Project Management. International Journal of Management \& Information Systems, 18(4), 233-240. doi: 10.19030/ijmis.v18i4.8820

Sieber, T. N., Petrini, O., \& Greenacre, M. J. (1998). Correspondence analysis as a tool in fungal taxonomy. Systematic and Applied Microbiology, 21(3), 433-441. doi: 10.1016/S0723-2020(98)80053-2

Silveira, D. T., \& Córdova, F. P. (2009). A pesquisa Científica. In T. E. Gerhardt \& D. T. Silveira (Eds.). Métodos de Pesquisa (pp. 31-42). Porto Alegre: Editora da UFRGS.

Stevenson, D. H., \& Starkweather, J. A. (2010). PM critical competency index: IT execs prefer soft skills. International Journal of Project Management, 28(7), 663-671. doi: 10.1016/j.ijproman.2009.11.008

The Standish Group International (1994). The Chaos Report (Vol. 53). Recuperado de https://www.standishgroup.com/sample_res earch_files/chaos_report_1994.pdf. Acesso em 18/abr/2019. 